\title{
The Impact of Family Environment upon Development of Life Skills and Psychological Hardiness among Adolescent Boys
}

\begin{abstract}
ABATRACT
The objective of the present study is to explore the role of family in developing life skills and psychological hardiness among adolescent boys. The study was conducted on a random sample of 300 male adolescents studying in government and private schools of Rajasthan. The data was collected with the help of life skills scale, psychological hardiness scale and family climate scale. Correlation was used to study life skills and psychological hardiness in relation to family environment among male adolescents. Regression was used to study family environment components of expressiveness, conflict, acceptance, cohesion, independence, active recreational orientation, organization and control and total family environment as predictors of life skills and psychological hardiness among male adolescents. The co relational analysis indicated that life skills are significantly correlated with all the eight dimensions of family environment except control dimension. Also, a significant relationship of control, challenge and global psychological hardiness with family environment and its dimensions was observed. The results of step-wise multiple regression revealed that only cohesiveness, active recreational orientation and organization dimension of family environment emerged as significant predictors of life skills among male adolescents. Further, the analysis revealed that total family environment emerged as a significant predictor of control, challenge and global psychological hardiness among adolescents. Implications of the results are discussed.
\end{abstract}

Mallika Dasgupta 1 , Radha Rani Sain 2

Keywords: Adolescents, Family environment, Life skills, Psychological hardiness

\section{INTRODUCTION:}

Family environment is considered as a system where the behaviour and relationship among all family members is interdependent. A stimulating physical environment, encouragement of achievement and affection are repeatedly linked to better performance of children. Every individual bears an impact of the environment in which she is brought up. Family is almost the exclusive environmental factor, which influences the first few primitive years of life. The family environment maintains its importance for the psychological development of the child.

\footnotetext{
${ }^{1}$ Junior Research Fellow, U.G.C

${ }^{2}$ Research Fellow, University of Rajasthan
}

(C) 2015, M Dasgupta, R Sain; licensee IJIP. This is an Open Access Research distributed under the terms of the Creative Commons Attribution License (http://creativecommons.org/licenses/by/2.0), which permits unrestricted use, distribution, and reproduction in any Medium, provided the original work is properly cited. 


\section{The Impact of Family Environment upon Development of Life Skills and Psychological Hardiness among Adolescent Boys}

Research shows that those adolescents shows more success in life who belong to households in which parents are both supportive and are accepting the child's needs for more psychological independence (Olsson et al. 1999; Madhu and Matla, 2004; Powell, 2006; Lee et al. 2006 and Deepshikha and Bhanot, 2011).

Life skills are defined as abilities, knowledge, attitudes and behaviour that must be learned for success in society. Life skills, being skills of adaptive and positive behaviours, enable individuals to enhance psychosocial competence. Life skills are found to affect academic success, peer relationship, family relationship, employment, and extra-curricular and leisure activities (Sharma, 2003; Slicker et al. 2005; Gambill et al. 2008; Gooding, 2009). Contextual factors influencing the development of life skills appear to include not only experiences within the school curriculum and the guidance and counseling programs but also talent development opportunities, and family and peer relationships (Yuen et al. 2010; Bouck, 2010). Life skills are accepted as valuable and worthwhile, can effectively influence the development of the positive attitude towards life (Papagcargious and Kavga, 2009; Sallee, 2007; Jone and Lavallee, 2008; Forneris et al., 2010).

Over the past 20 years, the psychological hardiness construct has emerged as a buffer in the relationship between stressors and illness and has been shown to enhance performance, conduct, and morale (Maddi, 1999). Thus, hardiness is a personality construct formed of three interrelated beliefs about oneself in interaction with the world, namely, commitment, control, and challenge. The commitment belief leads one to try to find, in whatever is being experienced, that which seems interesting and important, rather than lapsing to feelings of alienation. The control belief leads one to try to influence the directions and outcomes of whatever is going on, rather than lapsing into passivity and powerlessness and the challenge belief leads one to seek growth and wisdom through experience, whether positive or negative, rather than to feel entitled to easy comfort and security in a predictable world. It is a personality style that encourages human survival and the enrichment of life through development (Lambert and Lambert, 2003) and is a pervasive aspect of personality reflecting a general tendency towards psychological health (the opposite of neuroticism), extroversion, openness, and to a lesser extent agreeableness and conscientiousness. People who have courage (hardiness) to simultaneously favour involvement with others and events (commitment), keep trying to influence the outcomes going on around them learning from their influence the outcomes going on around them learning from their experiences, whether positive or negative (challenge), have more fulfilling, satisfying, resilient, and remarkable lives (Maddi et al., 2002).

The effects of family structure on child development are mitigated by such factors as family functioning and parenting. In addition, the outcomes for children from single-parent families vary with the distribution of other factors affecting the family such as the level of the mother's education and family income. The nature of children's family environment has a very strong 


\section{The Impact of Family Environment upon Development of Life Skills and Psychological Hardiness among Adolescent Boys}

effect on children's cognitive and behavioural development, and on the prevalence of childhood vulnerability. The factors within this environment that have been shown to have an impact on child development parenting skills, the cohesiveness of the family unity, the educational level and mental health of the mother, and the extent to which parents are actively engaged with their children. In fact, family environment is the quality and quantity of the cognitive, emotional and social support that has been available to the child within the home and connotes the psychological environment of home. Thus, a young person's social adjustment is not a thing apart, but is closely linked with his adjustment to his home and school relationships. It usually follows that an adolescent who experiences a normal and well-integrated home and school life carries over into all his other associations a similar wholesomeness of attitude and control of behaviour (Verma and Sangita, 1991; Field et al. 1995; Kokko and Pulkkinen, 2000 and Lai and Mcbride-Chang, 2001). On the basis of these observations, it was thought worthwhile to study family environment as a predictor of psychological hardiness among adolescents.

\section{OBJECTIVES}

- To study family environment as a predictor of life skills among male adolescents.

- To study family environment as a predictor of psychological hardiness among male adolescents.

\section{HYPOTHESES}

- Family environment and its dimensions will be the significant predictor of life skills among male adolescents.

- Family environment and its dimensions will be the significant predictor of psychological hardiness among male adolescents.

\section{OPERATIONAL DEFINITIONS OF THE TERMS USED}

1. Life Skills: It may be defined as "abilities for adoptive and positive behaviours that enable individual to deal effectively with the demands and challenges of everyday life". It includes decision making, problem solving, creative thinking, critical thinking, effective communication, interpersonal relationship, self-awareness empathy, coping with emotions and coping with stress (WHO, 1997) as measured by Life Skills Scale (Sharma, 2003).

2. Psychological Hardiness: Psychological hardiness refers to the constellation of three dispositions commitment, control and challenge and summation of three determining global hardiness as measured by psychological hardiness scale by Nowack (1990). The components of psychological hardiness are defined as:

Control: The control disposition is expressed as a tendency to feel and act as if one is influential (rather than helpless) in the face of the varied contingencies of life.

Commitment: The commitment disposition is expected as a tendency to involve oneself in (rather than experience alienation from) whatever one is doing or encounters.

Challenges: The challenge disposition is expressed as the belief that change rather than stability is normal in life and that the anticipation of changes are interesting incentives to 
growth rather than threats to security.

2. Family Environment: It refers to the quality and quantity of the cognitive, emotional and social support that has been available to the child with in the family and connotes the psychological environment of family as perceived by adolescents to be measured by Bhatia and Chadha (2004). It has eight components namely (i) cohesion, (ii) expressiveness, (iii) conflict, (iv) acceptance and caring, (v) independence, (vi) active recreational orientation, (vii) organization; and (viii) control.

i. Cohesion: It is degree of commitment, help and support of family members provide for one another.

ii. Expressiveness: It is the extent to which family members are encouraged to act openly and express their feelings and thoughts directly.

iii. Conflict: It refers to the amount of openly expressed aggression and conflict among family members.

iv. Acceptance and Caring: It is the extent to which the members are unconditionally accepted and the degree to which caring is expressed in the family.

v. Independence: It is the extent to which family members are assertive and independently make their own decisions.

vi. Active Re-creational Orientation: It refers to the extent of participation in social and recreational activities.

vii. Organization: It connotes the degree of importance of clear organization structure in planning family activities and responsibilities.

viii. Control: It is the degree of limit setting with in a family.

\section{METHOD \& PROCEDURE}

\section{Population of the study and sample}

The population of the study was the male adolescents studying in government as well as private schools located in Rajasthan. In the present study, random sampling method was used to select the sample. Eight schools (four governments and four private) were selected randomly from the list of various schools located in Jaipur \& Ajmer District of Rajasthan. The method of random sampling was again employed to select a sample of 300 male students from eight selected schools of Jaipur \& Ajmer district of Rajasthan. 


\section{Research tools}

The following tools were selected and used by the investigator in the present study:

1. Life Skills Scale by Sharma (2003) was used to measure life skills among adolescents. It is a 31 item scale which covers all the different areas of life skills viz. self-awareness, empathy, interpersonal relationship, communication, critical thinking, creative thinking, decision making, problem solving, coping with stress and coping with emotions. The adolescents were asked to mark the 31 statements as strongly agree, agree, uncertain, disagree or strongly disagree as per their level of agreement or disagreement with the statements. The scores ranged from 1 to 5 according to the Likert's scale, each positive statement getting a score of 5 for strongly agree and each negative statement getting a score of 5 for strongly disagree and so on.

2. Psychological Hardiness Scale by Nowack (1990) was used for measuring psychological hardiness among adolescents. This is a 30-items scale to be responded on 5-point rating i.e. (1) strongly agree (2) agree (3) neither agree nor disagree (4) disagree (5) and strongly disagree. The scale has 10 items each pertaining to challenge, control and commitment dimensions.

3. Family Environment Scale by Bhatia and Chadha (2004) was used to measure the family environment of adolescents in the present investigation. This scale measures family environment in terms of eight sub-dimensions viz. cohesion, expressiveness, conflict, acceptance and caring, independence, active re-creational orientation, organization and control.

\section{RESULTS \& DISCUSSION}

Correlation was used to study psychological hardiness in relation to family environment among adolescents. Regression was used to study family environment components of expressiveness, conflict, acceptance, cohesion, independence, active recreational orientation, organization and control and total family environment as predictors of psychological hardiness among adolescents.

\section{Life Skills in relation to Family Environment}

The table 1 shows the coefficients of correlation of life skills with the eight dimensions of family environment and the total family environment. It may be seen from the table 1 that the correlation coefficient of life skills with cohesiveness (0.357), expressiveness (0.210), conflict (0.235), acceptance (0.166), independence (0.181) and organization (0.261) dimensions of family environment is positive and significant at 0.01 level. It indicates that there is a significantly positive relationship of life skills with cohesiveness, expressiveness, conflict, acceptance, independence and organization dimensions of family environment. 
Table 1: Life Skills among Adolescents in Relation to Family Environment

\begin{tabular}{|c|c|c|}
\hline S.No. & Dimension & Life Skills \\
\hline 1. & Cohesiveness & $0.357 * *$ \\
\hline 2. & Expressiveness & $0.210 * *$ \\
\hline 3. & Conflict & $0.235 * *$ \\
\hline 4. & Acceptance & $0.166^{* *}$ \\
\hline 5. & Independence & $0.181 * *$ \\
\hline 6. & Active Recreational Orientation & $-0.162 * *$ \\
\hline 7. & Organization & $0.261 * *$ \\
\hline 8. & Control & -0.019 \\
\hline 9. & Total Family Environment & $0.263 * *$ \\
\hline
\end{tabular}

The correlation coefficient of life skills with active recreational orientation $(0.162)$ dimension is negative and significant at 0.01 level. It shows that there is a significant and negative relationship of life skills with active recreational orientation dimension of family environment. The correlation coefficient of life skills with control dimension of family environment is not significant even at 0.05 level. The correlation coefficient of life skills with total family environment $(0.263)$ is positive and significant at 0.01 level.

\section{Family environment as predictor of life skills among adolescents}

From the result of correlation analysis, it was revealed that all the dimensions of family environment are significantly related to life skills among adolescents except the control dimension of family environment. Since the purpose of the study was to study family environment as the predictor of life skills among adolescents, stepwise multiple regression was carried out. Only the values of coefficient of correlation (r) and multiple correlation (R) determining the total effect of contributing factors, $\mathrm{R}^{2}$ and $\mathrm{R}^{2}$ change along with percentage variance in the set of predictors are reported in the table 2.

Table 2: Family Environment as a Predictor of Life Skills among Adolescents (N=300)

\begin{tabular}{|c|l|c|c|c|c|}
\hline S.No. & Dimension of Family Environment & $\mathbf{R}$ & $\mathbf{R}^{\mathbf{2}}$ & $\begin{array}{c}\mathbf{R}^{\mathbf{2}} \\
\text { Change }\end{array}$ & \% Variance \\
\hline 1. & Cohesiveness & 0.357 & 0.127 & 0.127 & $12.7 \%$ \\
\hline 2. & Active Recreational Orientation & 0.462 & 0.214 & 0.086 & $8.6 \%$ \\
\hline 3. & Organization & 0.490 & 0.240 & 0.026 & $2.6 \%$ \\
\hline
\end{tabular}




\section{The Impact of Family Environment upon Development of Life Skills and Psychological Hardiness among Adolescent Boys}

The table 2 shows the results of step-wise multiple regression. It shows that only cohesiveness, active recreational orientation and organization dimension of family environment emerged as significant predictors of life skills among adolescents while explaining only $12.7 \%$, $8.6 \%$ and $2.6 \%$ of the variance respectively in life skills among adolescents. Cohesiveness and organization dimensions of family environment were found to be the positive contributors to life skills among adolescents. However, active recreational orientation was found to be a negative contributor towards life skills among adolescents.On the basis of the above results, it may be concluded that out of these three predictors, cohesiveness, dimension of family environment emerged as the most significant predictor of life skills among adolescents followed by active recreational orientation (ARO) and organization dimensions of family environment.

\section{Psychological Hardiness in relation to Family Environment}

The table 3 shows the correlation coefficients of psychological hardiness and its components with family environment and its dimensions. The table 3 reveals that the correlation coefficient of commitment component of psychological hardiness with any of the dimensions of family environment as well as total family environment is not significant even at 0.05 level indicating than there is no significant relationship of commitment dimension of psychological hardiness with any of the family environment components. It may be further observed from the table 3 that the correlation coefficient of control dimension of psychological hardiness with cohesiveness (-0.248), conflict (-0.313), acceptance (-0.206), independence (-0.228), active recreational orientation $(-0.205)$, control $(-0.172)$ dimension of family environment is significant at 0.01 level.

The correlation coefficient of control dimension of psychological hardiness with expressiveness dimension of family environment is significant at 0.05 level. It indicates that there is a significant relationship of control dimensions of psychological hardiness with cohesiveness, expressiveness, conflict, acceptance, independence, active recreational orientation and control dimension of family environment. The correlation coefficient of control dimension of psychological hardiness with organization (0.111) dimension of family environment is not significant even at 0.05 level. The correlation coefficient of control dimension of psychological hardiness with total family environment (0.336) is significant at 0.01 level. 
Table 3: Psychological Hardiness among Adolescents in relation to Family Environment

\begin{tabular}{|c|c|c|c|c|c|}
\hline S. No. & $\begin{array}{l}\text { Dimensions of } \\
\text { Family } \\
\text { Environment }\end{array}$ & Commitment & Control & Challenge & $\begin{array}{c}\text { Psychological } \\
\text { Hardiness }\end{array}$ \\
\hline 1. & Cohesiveness & 0.58 & $-0.248 * *$ & $-0.247 * *$ & $-0.244 * *$ \\
\hline 2. & Expressiveness & -0.046 & $0.144 *$ & $0.118^{*}$ & $0.167 * *$ \\
\hline 3. & Conflict & -0.039 & $-0.313 * *$ & $-0.248 * *$ & $-0.329 * *$ \\
\hline 4. & Acceptance & 0.035 & $-0.206 * *$ & $-0.280 * *$ & $0.250 * *$ \\
\hline 5. & Independence & 0.009 & $0.228 * *$ & $0.238 * *$ & $0.253 * *$ \\
\hline 6. & $\begin{array}{l}\text { Active } \\
\text { Recreational } \\
\text { Orientation }\end{array}$ & -0.026 & $0.205^{* *}$ & $-0.161 * *$ & $0.190 * *$ \\
\hline 7. & Organization & -0.029 & 0.111 & -0.084 & $0.122 *$ \\
\hline 8. & Control & 0.058 & $-0.172 * *$ & -0.086 & $-0.115^{*}$ \\
\hline 9. & $\begin{array}{l}\text { Total Family } \\
\text { Environment }\end{array}$ & 0.022 & $0.336 * *$ & $0.309 * *$ & $0.345 * *$ \\
\hline
\end{tabular}

$\mathrm{p}<0.05^{*} ; \mathrm{p}<0.01^{* *}$

The table 3 further shows that the correlation coefficient challenge dimension of psychological hardiness with cohesiveness (-0.247), conflict (-0.248), acceptance (0.280), independence (0.238) and active recreational orientation (0.161), dimension of family environment is significant at 0.01 level. The correlation coefficient of challenge dimension of psychological hardiness with expressiveness (-0.118) dimensions of family Environment is significant at 0.05 level. It indicates that there is a significant relationship of challenge dimensions of psychological hardiness with cohesiveness, expressiveness, conflict, acceptance, independence and active recreational orientation. The correlation coefficient of challenge dimension of psychological hardiness with organization (-0.084) and control (-0.086) dimension of family environment is not significant even at 0.05 level. The correlation coefficient of challenge dimension of psychological hardiness with total family environment $(-0.309)$ is significant at 0.01 level.

The perusal table 3 further reveals that the correlation coefficient of psychological hardiness with cohesiveness (-0.244), expressiveness (0.167), conflict (0.329), acceptance (0.250), independence (0.253) and active recreational orientation (0.190) dimension of family environment is significant at 0.01 level and the correlation coefficient of psychological hardiness with organization (0.122) and control (-0.11) dimension of family environment significant at 0.05 level. It indicates that there is significant relationship of psychological hardiness with all the dimensions of the family environment. The correlation coefficient of psychological hardiness with total family environment $(0.345)$ is significant at 0.01 level. It indicates that psychological 
hardiness among adolescents is significantly related to all the eight family environment components as well as total family environment.

\section{Family environment as predictor of psychological hardiness among adolescents}

The table 4 shows that the result of step-wise multiple regression analysis of psychological hardiness in relation to family environment.

The results of step-wise multiple regressions revealed that none of the family environment dimensions as well as the total family environment emerged as a significant predictor of commitment dimension of psychological hardiness among adolescents. The perusal of the table 4 reveals that total family environment emerged as a significant predictor of control dimension of psychological hardiness among adolescents while explaining only $11 \%$ of the variance in control dimension of psychological hardiness among adolescents.

Table 4: Family Environment as a Predictor of Psychological Hardiness among Adolescents

\begin{tabular}{|c|l|c|c|c|c|c|}
\hline S.No & \multicolumn{1}{|c|}{$\begin{array}{c}\text { Dependent } \\
\text { Variable }\end{array}$} & $\mathbf{R}$ & $\mathbf{R}^{\mathbf{2}}$ & $\begin{array}{c}\mathbf{R}^{\mathbf{2}} \\
\text { Change }\end{array}$ & F-value & $\begin{array}{c}\% \\
\text { Variance }\end{array}$ \\
\hline 1. & Control & 0.336 & 0.113 & 0.110 & $37.82^{* *}$ & $11 \%$ \\
\hline 2. & Challenge & 0.309 & 0.095 & 0.092 & $31.42^{* *}$ & $9.2 \%$ \\
\hline 3. & $\begin{array}{l}\text { Psychological } \\
\text { Hardiness }\end{array}$ & 0.345 & 0.119 & 0.116 & $40.31^{* *}$ & $11.6 \%$ \\
\hline
\end{tabular}

Further, the table 4 showed that family environment emerged as a significant predictor of challenge dimension of psychological hardiness among adolescents while explaining only $9.2 \%$ of the variance in challenge dimension of psychological hardiness among adolescence. The table 4 indicates that family environment emerged as a significant predictor of psychological hardiness among adolescents while explaining only $11.61 \%$ of variance in psychological hardiness among adolescents. It may be concluded that family environment was found to be a positive contributor to control, challenge dimension of psychological hardiness and total psychological hardiness among adolescents.

On the basis of above results, it may be concluded that total family environment emerged as a significant predictor of control and challenge dimension of psychological hardiness and as well as total psychological hardiness among adolescents. However, none of the family environment components or total family environment emerged as a significant predictor of commitment dimension of psychological hardiness among adolescents. Similarly, family environment was also found to be a significant predictor of psychological hardiness among adolescents. These results find support from a number of earlier researches (Lifton et al. 2005; Maddi et al. 2009). 


\section{EDUCATIONAL IMPLICATIONS}

1. As the study revealed cohesiveness, organization and active recreational orientation were important contributing factors influencing the level of life skills in the adolescents, so it becomes the duty of the parents to have more cohesiveness and organization in the family. Also, they should be made aware about the importance of a conducive family environment in the course of adolescent development.

2. Total family environment was found to be a significant predictor of control, challenge and global psychological hardiness among adolescents. Hence, it is the family from where hardy attitudes begin to develop among adolescents. So, it is essential for the parents to develop such a conducive family environment for the adolescents where they are given enough opportunities to develop self-control, challenge accepting attitudes and a hardy personality.

3. Life skills training and hardiness training should be an important aspect of school enrichment programme and the families too need to be strengthened as hardy individuals having life skills take the lead in charge, show greater performance, leadership, morale, conduct and health. Hardiness training approach can help adolescents in building attitudes and managing resources which improve the individual and can help turn adversity to advantage.

\section{REFERENCES}

1. Bhatia, N. K. and Chadha, B. S. (1993) Manual for Family Environment Scale. Lucknow: Ankur Psychological Agency.

2. Bouck, E.C. (2010) Reports of Life Skills Training for Students with Intellectual Disabilities in and Out of School. Journal of Intellectual Disability Research,54 (12), 1093-1103.

3. Deepshikha and Bhanot, Suman (2011) Role of Family Environment on Socio-Emotional Adjustment of Adolescent Girls in Rural Areas of Eastern Uttar Pradesh. Journal of Psychology, 2(1), 53-56.

4. Field, T., Lang, C., Yando, R. and Bendell, D. (1995) Adolescents' Intimacy with Parents and Friends. Adolescence, 30(117), 133-140.

5. Forneris, T., Fries, E., Meyer, A., Buzzard, M., Uquy, S., Ramakrishnan, R., Lewis, C. and Danish, S. (2010) Results of a Rural School based Peer-led Intervention for Youth: Goals for Health. Journal of School Health, 80(2), 57-65.

6. Gambill, J, M., Moss, L.A. and Vescogni, C.D. (2008) The Impacts of Study Skills and Organizational Submission. Retrieved from www.eric.ed.gov.

7. Jones, M.I. and Lavallee, D. (2008) Exploring the Life Skills needs of British Adolescent Athletes. Psychology of sport and Exercise, 10(1), 159-167.

8. Kokko, K. and Pulkkinen, L. (2000) Aggression in Childhood and Long-Term Unemployment in Adulthood: A Cycle of Maladaptation and Some Protective Factors. Development Psychology, 36(4), 39-41.

9. Lai, KaWai and McBride-Chang, Catherine (2001) Suicidal Ideation, Parenting Style and Family Climate among Hong Kong Adolescents. International Journal of Psychology, 36(2), 81-87. 
10. Lambert, Vickie A. and Lambert, Clinton, E. (2003) Psychological Hardiness, Workplace Stress and Related Stress Reduction Strategies. Nursing and Health Sciences, 5, 181-184.

11. Lee, M.T., Wong, B.P., Chow, B.W. and McBride-Chang, C. (2006) Predictors of Suicide Ideation and Depression in Hong Kong Adolescents: Perceptions of Academic and Family Climates. Suicide Life Threat Behavior, 36(1), 82-96.

12. Lifton, Donald, Seay, Sandra, McCarly, Nancy, Olive-Taylor, Rebeca, Seeger, Richard and Bigbee, Dalton (2005) Correlating Hardiness with Graduation Persistence. Paper Presented at Annual Meeting of the American Society of Business and Behavioural Sciences (ASBBS).

13. Maddi, S.R. (1999) Comments on Trends in Hardiness Research and Theorizing. Consulting Psychology Journal: Practice and Research, 51, 67-71.

14. Maddi, S.R., Harvey, Richard, H., Khoshaba, Deborah M., Fazel, Mostafa and Resurrection, Nephthys (2009) Personality Construct of Hardiness, IV: Positive Cognitions and Emotions Concerning Oneself and Developmentally Relevant Activities. Journal of Humanistic Psychology, 49(3), 292.

15. Maddi, Salvatore R., Khoshaba, Deborah, M., Persoci, Michele, Lu, John, Harvey, Richard and Bleecker, Felicia (2002) The Personality Construct of Hardiness. Journal of Research in Personality, 36, 72-85.

16. Madhu, Sylvester N. and Matla, Ma-Queen, P. (2004) Family Environmental Factors as Correlates for Adolescent Suicidal Behaviours in the Limpopo Province of South Africa. Social Behaviour and Personality: An International Journal, 32(4), 341-353.

17. Olsson, G.I., Nordstorm, M.L. Arinell, H. and Von, Knorring, A.L. (1999) Adolescents Depression: Social Network and Family Climate - A Case Control Study. Journal of Child Psychology and Psychiatry, 40(2), 227-237.

18. Papageorgiou, D.E., and Kavga, A. (2009) Evaluation of Life Skills in Students of Nursing: a Descriptive Study. International Journal of Caring Science, 2(3), 135-141. Retrieved from www.coring science.org.

19. Powell, Leah A. (2006) Family Strengths, Stress and Well-Being among Troubled and Well Adjusted Adolescents. Dissertation Abstracts International, 67(5), 1659-A.

20. Sallee, J.A. (2007) Perceived Effectiveness of Youth-Adult Partnerships on Enhancing Life Skill Development Through 4-H Dissertation. Oklahoma State University. Retrieved from http://dc.library.okstate.edu.

21. Sharma, S. (2003) Measuring Life Skills of Adolescents in Secondary School of Kathmandu: An Experience. Kathmandu University Medical Journal, 1(3), 170-176.

22. Slicker, Ellen K., Picklesimer, Billie, K., Guzak, Andrea K. and Fuller, Dana K. (2005) The Relationship of Parenting Style to Older Adolescent Life Skills Development in the United States. Young, 13, 227-245.

23. Verma, B.P. and Sangita (1991) Locus of Control and and Self-Esteem as a Function of Family-Climate. Asian Journal of Psychology and Education, 24(5-6), 2-5.

24. Yuen, M., Chan, R.M.C., Gysbers, N.C., Lau, P.S.Y., Lee, Q., Shea, P.M.K., Fong, R.W. and Chung, Y.B. (2010) Enhancing life skills Development: Chinese Adolescent's Perception. Pastoral Care in Education, 28(4), 295-310. 